\title{
Prognostic Impact of Preoperative Albumin-to-Globulin Ratio in Patients with Colon Cancer Undergoing Surgery with Curative Intent
}

\author{
HIROYUKI FUJIKAWA, YUJI TOIYAMA, YASUHIRO INOUE, HIROKI IMAOKA, TADANOBU SHIMURA, \\ MASATO OKIGAMI, HIROMI YASUDA, JUNICHIRO HIRO, SHIGEYUKI YOSHIYAMA, SUSUMU SAIGUSA, \\ MINAKO KOBAYASHI, MASAKI OHI, TOSHIMITSU ARAKI, YASUHIKO MOHRI and MASATO KUSUNOKI \\ Department of Gastrointestinal and Pediatric Surgery, Division of Reparative Medicine, \\ Institute of Life Sciences, Mie University Graduate School of Medicine, Tsu, Japan
}

\begin{abstract}
Aim: To identify predictors of poor prognosis of patients with colon cancer (CC) who underwent surgery with curative intent, we investigated the association between the albumin to globulin ratio (AGR) with clinicopathological findings such as overall (OS) and disease-free (DFS) survival. Patients and Methods: We conducted a retrospective study of clinicopathological findings, including preoperative laboratory data, for 248 patients with stage I-III CC. Results: Patients with low AGR had shorter DFS and OS compared to those with high AGR. Multivariate analyses identified low $A G R$ as an independent variable independently associated with recurrence and poor prognosis of patients with CC who underwent surgery with curative intent regardless of lymphnode metastasis. Conclusion: The preoperative AGR was an independent predictor of recurrence and poor prognosis of patients with CC who underwent surgery with curative intent. The AGR indicates that these patients may benefit from intensive adjuvant therapy.
\end{abstract}

Colorectal cancer (CRC) is one of the most common malignant tumours worldwide (1). Despite radical surgery and the development of adjuvant therapies such as chemotherapy and chemoradiotherapy, disease recurs in approximately 15$30 \%$ of patients $(2,3)$. The National Comprehensive Cancer Network (NCCN) Guidelines and the European Society for Medical Oncology (ESMO) Consensus Guidelines for

Correspondence to: Hiroyuki Fujikawa, Department of Gastrointestinal and Pediatric Surgery, Mie University Graduate School of Medicine, 2-174 Edobashi, Tsu, Mie 514-8507, Japan. Tel: +81 592315294, Fax: +81 592326968, e-mail: f0609@ clin.medic.mieu.ac.jp

Key Words: Albumin to globulin ratio, colon cancer, prognosis, recurrence. patients with colon cancer (CC) recommend postoperative adjuvant chemotherapy for patients with stage III CC and those with high-risk stage II disease (4-6). These guidelines recommend that patients with stage I as well as those with low-risk stage II CC should be treated with surgery alone (46). However, disease does not recur in $50 \%$ of patients with stage III CC who are not administered adjuvant chemotherapy (7), whereas disease recurs in 10-20\% of patients with earlystage disease (stages I and II) who were managed according to these guidelines $(3,8)$. Therefore, better prognostic markers are required to predict oncological outcomes in order to improve management of these patients.

An elevated systemic inflammatory response (SIR) in patients with cancer is associated with poor outcomes (9-11). A SIR promotes disease progression through changes in the tumour microenvironment (12). SIR markers mainly include the levels of circulating neutrophils, lymphocytes, platelets, acute-phase proteins such as C-reactive protein (13) and albumin (14). The indices calculated using these markers, such as the Glasgow prognostic score (15), neutrophil-tolymphocyte ratio (16) and platelet-to-lymphocyte ratio (17), serve as useful prognostic factors for predicting the outcomes of patients with cancer, including those with $\mathrm{CC}$.

The albumin-to-globulin ratio (AGR) is mainly used as a clinical indicator for multiple myeloma or other immunoproliferative diseases (18). The albumin level generally reflects nutritional status as well as inflammation (19), and the levels and composition of serum globulins reflect immunity and inflammation (14). Hypoalbuminaemia and hyperglobulinaemia (low AGR) may be associated with poor prognosis associated with malnutrition and active inflammation. The AGR is, therefore, an emerging prognostic factor of patients with CC (20-22), breast (23), lung (24) and urothelial (25) cancer. However, insufficient data are available to evaluate the association of AGR with the prognosis of $\mathrm{CC}$. 
Table I. Association between clinicopathological findings and preoperative albumin to globulin ratio (AGR) of patients with stage I-III colon cancer who underwent surgery with curative intent.

\begin{tabular}{|c|c|c|c|c|}
\hline Category & Factor & Number & AGR $($ mean \pm SD) & $p$-Value \\
\hline \multirow[t]{2}{*}{ Age } & $<70$ Years & 126 & $1.396 \pm 0.278$ & 0.14 \\
\hline & $\geq 70$ Years & 122 & $1.357 \pm 0.278$ & \\
\hline \multirow[t]{2}{*}{ Gender } & Female & 118 & $1.373 \pm 0.275$ & 0.77 \\
\hline & Male & 130 & $1.38 \pm 0.281$ & \\
\hline \multirow[t]{2}{*}{ Location } & Left colon & 116 & $1.383 \pm 0.275$ & 0.74 \\
\hline & Right colon & 132 & $1.371 \pm 0.281$ & \\
\hline \multirow{2}{*}{ Tumor size } & $<40 \mathrm{~mm}$ & 124 & $1.474 \pm 0.243$ & $<0.0001$ \\
\hline & $\geq 40 \mathrm{~mm}$ & 124 & $1.277 \pm 0.279$ & \\
\hline \multirow[t]{2}{*}{ Histology } & Well, moderately differentiated & 226 & $1.397 \pm 0.267$ & 0.0011 \\
\hline & Poorly differentiated, mucinous & 22 & $1.152 \pm 0.312$ & \\
\hline \multirow[t]{2}{*}{ Vascular invasion } & Absent & 133 & $1.407 \pm 0.279$ & 0.041 \\
\hline & Present & 115 & $1.342 \pm 0.273$ & \\
\hline \multirow[t]{2}{*}{ Lymphatic invasion } & Absent & 64 & $1.441 \pm 0.277$ & 0.021 \\
\hline & Present & 184 & $1.354 \pm 0.276$ & \\
\hline \multirow[t]{2}{*}{ T Stage } & $\mathrm{T} 1-\mathrm{T} 3$ & 207 & $1.41 \pm 0.257$ & 0.0001 \\
\hline & $\mathrm{T} 4$ & 41 & $1.2 \pm 0.315$ & \\
\hline \multirow[t]{2}{*}{ Lymph node metastasis } & Absent & 157 & $1.39 \pm 0.269$ & 0.345 \\
\hline & Present & 91 & $1.35 \pm 0.292$ & \\
\hline \multirow[t]{2}{*}{ CEA } & $<5 \mathrm{ng} / \mathrm{ml}$ & 142 & $1.412 \pm 0.254$ & 0.054 \\
\hline & $\geq 5 \mathrm{ng} / \mathrm{ml}$ & 106 & $1.337 \pm 0.301$ & \\
\hline
\end{tabular}

SD: Standard deviation; CEA: carcinoembryonic antigen.

Here we investigated the association between AGR and clinicopathological findings, including overall (OS) and disease-free (DFS) survival in patients with CC who underwent surgery with curative intent.

\section{Patients and Methods}

Patients. We enrolled 248 patients who underwent potentially curative surgery for CC at our Institution between January 1, 2002, and December 31,2012. Curative resection was defined as the absence of gross residual tumour from the surgical bed and a resection margin that was pathologically negative for tumour invasion. Chemotherapy was not administered to patients before surgery. The patients were classified according to the TNM Classification of Union for International Cancer Control (Seventh Edition) (26). Administration of fluoropyrimidine-based regimens commenced by 8 weeks after surgery with curative intent and continued for 6 months for patients with stage III and high-risk stage II CC. Patients granted their informed consent and were followed-up according to our standard protocol every 12-16 weeks for at least 1 year. The protocol included tumour-marker studies, computed tomography, endoscopic examinations, ultrasonography and chest radiography.

Clinical and laboratory data collection. Data collected from inpatient and outpatient records included age and sex; pathology such as tumour staging, lymph node metastasis, tumour-cell differentiation, lymphovascular invasion, and tumour size; carcinoembryonic antigen (CEA) levels at diagnosis; DFS; and OS. Analysis of peripheral blood was performed before surgery and included the determination of protein and albumin levels. The AGR was calculated as follows: albumin/(total protein-albumin). The cutoff value for CEA was $5 \mathrm{ng} / \mathrm{ml}$, according to the normal range used in our hospital. Receiver operating characteristic (ROC) curves were established for determining the cutoff value for the AGR (1.32) for analysing prediction of recurrence by Youden's index. The Institutional Review Boards of Mie University Hospital approved the protocol for blood collection and subsequent analyses (protocol number: 2216). The study was conducted in accordance with the guidelines of the 1975 Declaration of Helsinki. The requirement for informed consent, except as noted above, was waived because of the retrospective nature of the study.

Statistical analysis. Data are presented as the mean \pm standard deviation (SD). Comparisons were performed using the MannWhitney test. The optimal cutoff for recurrence were obtained from Youden's index. Briefly, the optimal cutoff value was determined at the point on the ROC curve with the maximum Youden's index (sensitivity + specificity -1 ). Survival curves were generated using the Kaplan-Meier product-limit method, and comparisons were performed using the log-rank test. Prognostic factors were identified using univariate and multivariate analyses (Cox proportional hazards regression model). All $\mathrm{p}$-values were two-sided, and a value $p<0.05$ was considered significant. All statistical analyses were performed using JMP 11 (SAS Institute Inc., Cary, NC, USA).

\section{Results}

Patient characteristics and the association between clinicopathological findings and preoperative AGR. This retrospective study included 118 women and 130 men aged 2788 years (median $=70$ years). The median follow-up was 49.7 
A

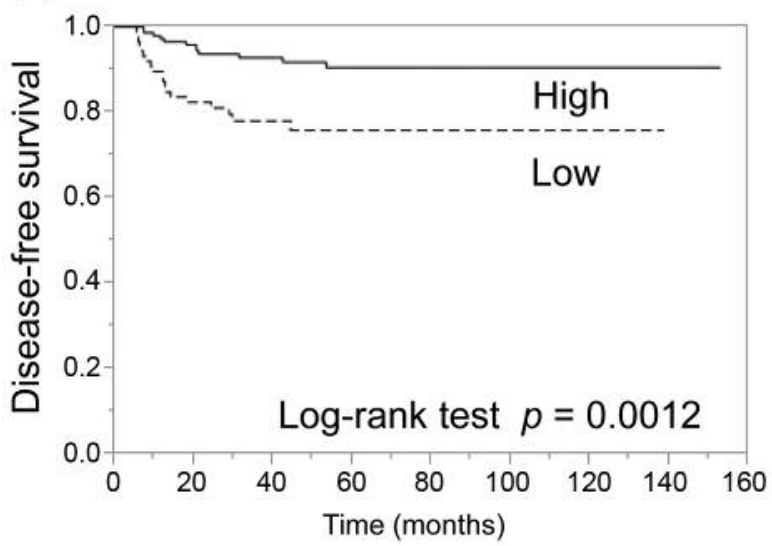

B

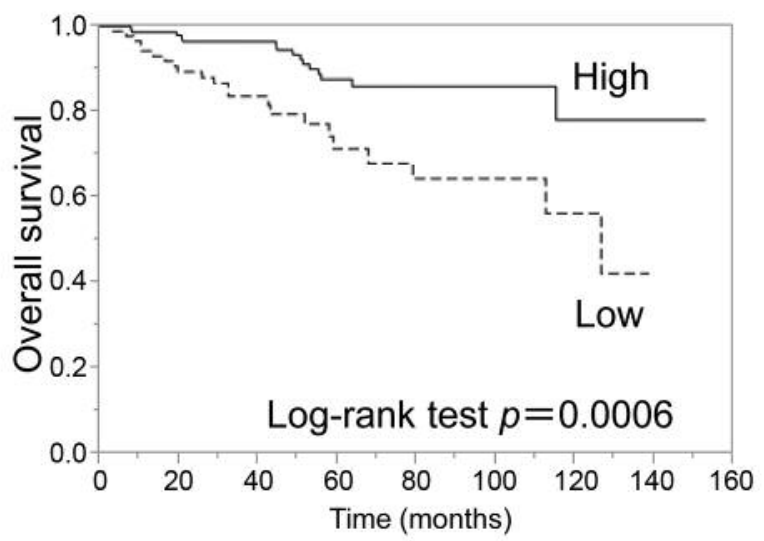

Figure 1. Analysis of the association of the albumin to globulin ratio (AGR) with the survival of patients with colon cancer who underwent surgery with curative intent. Kaplan-Meier analysis of disease-free (A) and overall (B) survival in patients with colon cancer according to their preoperative AGR. Patients were divided into groups with high or low AGR according to whether their AGR was 1.32 or higher, or lower than 1.32, respectively.

months $[95 \%$ confidence interval $(\mathrm{CI})=48.6-57.0$ months]. Sixty-two patients (25\%) had stage I, $95(38.3 \%)$ had stage II, and $91(36.7 \%)$ had stage III CC. Disease recurred in 31 patients $(12.5 \%)$ after surgery with curative intent, of which eight patients had stage II, and 23 had stage III disease. The mean AGR was 1.38 and did not differ significantly with stage. Detailed clinicopathological data and the association between clinicopathological findings and preoperative AGR of patients who underwent surgery with curative intent are presented in Table I. The AGR was significantly lower in patients with tumour progression such as that indicated by a large tumour (>40 mm), T4 tumour, venous invasion, lymphatic invasion and histology (poorly and mucinous adenocarcinoma).

Survival analyses according to preoperative AGR. DFS and OS subdivided according to preoperative AGR are shown in Figure 1. DFS (Figure 1A) and OS (Figure 1B) were significantly shorter for patients with low AGR compared to those with high AGR (DFS, $p=0.0012$; OS, $p=0.0006$, respectively).

Prognostic factors associated with poor survival. Univariate analysis of DFS showed that tumour size $\geq 40 \mathrm{~mm}$, T4 tumour, lymph node metastasis, venous invasion, lymphatic invasion, high serum CEA level $(\geq 5 \mathrm{ng} / \mathrm{ml})$ and low AGR $(<1.32)$ were factors significantly associated with early recurrence (Table II). Multivariate analysis of DFS showed that lymph node metastasis [hazard ratio $(\mathrm{HR})=5.56,95 \%$ confidence interval $(\mathrm{CI})=2.35-15.4, p<0.0001)]$ and low AGR $(\mathrm{HR}=2.93,95 \% \quad \mathrm{CI}=1.42-6.69, p=0.0072)$ were independent factors associated with poorer DFS (Table II). Univariate analysis of OS revealed that histology (poorly differentiated and mucinous), venous invasion and low AGR
$(<1.32)$ were significant factors associated with poor prognosis (Table III). Multivariate analysis of OS revealed that low AGR (HR=2.67, 95\% $\mathrm{CI}=1.33-5.5, p=0.0058)$ was an independent predictor of poor prognosis (Table III).

Survival associated with preoperative AGR in patients without lymph node metastasis. The analyses of DFS and OS of patients with stage I-II CC according to preoperative AGR show that for patients without lymph node metastasis, DFS (Figure 2A) and OS (Figure 2B) were significantly shorter in those with low AGR compared to those with high AGR (DFS, $p=0.0015$; OS , $p=0.0097$ ).

Prognostic factors associated with poor survival of patients without lymph node metastasis. Univariate analysis of DFS showed that age $\geq 70$ years, poorly differentiated and mucinous histology, and low AGR $(<1.32)$ were significantly associated with poor prognosis in patients without lymph node metastasis (Table IV). Multivariate analysis revealed that increasing age $(\mathrm{HR}=0.15,95 \% \mathrm{CI}=0.01-0.82, p=0.027)$ and low AGR $(\mathrm{HR}=12.4,95 \% \mathrm{CI}=1.97-239.1, p=0.0054)$ were significant independent predictors of poorer DFS of patients without lymph node metastasis (Table IV). Univariate analysis of OS also revealed that poorly differentiated and mucinous histology, venous invasion and low AGR $(<1.32)$ were significantly associated with poor prognosis (Table V). Multivariate analysis revealed that vascular invasion $(\mathrm{HR}=3.45,95 \% \mathrm{CI}=1.17-12.6, p=0.025)$ and low AGR $(\mathrm{HR}=3.17,95 \% \mathrm{CI}=1.11-10.3, p=0.031)$ were significant independent predictors of poor OS (Table V).

Kaplan-Meier survival analysis according to preoperative AGR in patients with lymph node metastasis. DFS (Figure $3 \mathrm{~A}$ ) and OS (Figure 3B) were significantly shorter for 
Table II. Cox proportional hazards model analysis of the predictors of disease-free survival of patients with stage I-III colon cancer who underwent surgery with curative intent.

\begin{tabular}{|c|c|c|c|c|}
\hline Factor & Univariate HR $(95 \% \mathrm{CI})$ & $p$-Value & Multivariate HR $(95 \% \mathrm{CI})$ & $p$-Value \\
\hline Gender: $\mathrm{M} v s . \mathrm{F}$ & $0.85(0.42-1.73)$ & 0.65 & & \\
\hline Age: $\geq 70 v s .<70$ Years & $0.57(0.26-1.17)$ & 0.12 & & \\
\hline Location: Right $v s$. left & $1.03(0.51-2.11)$ & 0.93 & & \\
\hline Tumor size: $\geq 40 v s .<40 \mathrm{~mm}$ & $2.55(1.2-5.86)$ & 0.014 & $1.2(0.53-3.0)$ & 0.49 \\
\hline Histology: Well/mod diff $v s$. poorly diff, muc & $2.2(0.74-5.27)$ & 0.14 & & \\
\hline Tumor invasion: T4 vs. non-T4 & $4.25(2.04-8.63)$ & 0.0002 & $1.46(0.63-3.25)$ & 0.36 \\
\hline Lymph node metastasis: Yes $v s$. no & $5.62(2.62-13.4)$ & $<0.0001$ & $5.56(2.35-15.4)$ & $<0.0001$ \\
\hline Vascular invasion: Yes $v s$. no & $3.12(1.48-7.15)$ & 0.0024 & $2.06(0.93-5.03)$ & 0.076 \\
\hline Lymphatic invasion: Yes vs. no & $11.2(2.4-199)$ & 0.0004 & $3.16(0.62-57.8)$ & 0.19 \\
\hline CEA: $\geq 5 v s .<5 \mathrm{ng} / \mathrm{ml}$ & $2.23(1.09-4.77)$ & 0.029 & $1.41(0.65-3.17)$ & 0.38 \\
\hline AGR: Low $(<1.32) v s$. high $(\geq 1.32)$ & $3.12(1.53-6.61)$ & 0.0017 & $2.93(1.34-6.69)$ & 0.0072 \\
\hline
\end{tabular}

M: Male; F: female; mod: moderately; diff: differentiated; muc: mucinous; CEA: carcinoembryonic antigen; AGR: albumin-to-globulin ratio; HR: hazard ratio; CI: confidence interval.

Table III. Cox proportional hazards model analysis of predictors of overall survival of patients with stage I-III colon cancer patients who underwent surgery with curative intent.

\begin{tabular}{|c|c|c|c|c|}
\hline Factor & Univariate HR $(95 \% \mathrm{CI})$ & $p$-Value & Multivariate HR (95\% CI) & $p$-Value \\
\hline Gender: $\mathrm{M} v s . \mathrm{F}$ & $1.83(0.94-3.7)$ & 0.073 & & \\
\hline Age: $\geq 70 \mathrm{vs} .<70$ Years & $1.46(0.76-2.84)$ & 0.25 & & \\
\hline Location: Right $v s$. left & $0.77(0.39-1.46)$ & 0.42 & & \\
\hline Tumor size: $\geq 40 \mathrm{vs} .<40 \mathrm{~mm}$ & $1.26(0.66-2.48)$ & 0.48 & & \\
\hline Histology: Well/mod diff $v s$. poorly diff, muc & $3.17(1.27-6.94)$ & 0.016 & $1.99(0.78-4.49)$ & 0.17 \\
\hline Tumor invasion: T4 vs. non-T4 & $3.06(1.51-5.91)$ & 0.0026 & $1.51(0.69-3.12)$ & 0.29 \\
\hline Lymph node metastasis: Yes $v s$. no & $2.23(1.17-4.31)$ & 0.015 & $1.98(0.99-4.02)$ & 0.0501 \\
\hline Vascular invasion: Yes $v s$. no & $3.1(1.53-6.78)$ & 0.0013 & $2.04(0.95-4.72)$ & 0.066 \\
\hline Lymphatic invasion: Yes $v s$. no & $3.29(1.18-13.7)$ & 0.019 & $1.17(0.37-5.27)$ & 0.79 \\
\hline CEA: $\geq 5 v s .<5 \mathrm{ng} / \mathrm{ml}$ & $1.94(0.99-3.83)$ & 0.051 & & \\
\hline AGR: Low $(<1.32) v s$. high $(\geq 1.32)$ & $2.99(1.56-5.89)$ & 0.001 & $2.67(1.33-5.5)$ & 0.0058 \\
\hline
\end{tabular}

M: Male; F: female; mod: moderately; diff: differentiated; muc: mucinous; CEA: carcinoembryonic antigen; AGR: albumin-to-globulin ratio; HR: hazard ratio; CI: confidence interval.

patients with a low AGR compared with those with a high AGR (DFS, $p=0.0288$; OS, $p=0.0075$ ).

\section{Discussion}

The TNM staging system provides the most reliable information for prognosis and treatment planning for patients with CRC. According to the TNM staging system and certain prognostic factors such as pathology and clinical information, adjuvant chemotherapy after curative resection is administered as the preferred treatment option (27). However, postoperative adjuvant chemotherapy sometimes is excessive when administered to patients with stage III disease, and surgery alone can be insufficiently beneficial for patients with stage I-II disease, according to prognostic data (28). These problems may be resolved by the eventual availability of emerging prognostic markers that can more accurately predict the prognosis of patients with $\mathrm{CC}$ at high risk of recurrence or those with a poor prognosis.

Although AGR is a prognostic factor for patients with cancer (20-25), the mechanisms that influence recurrence and survival are not understood. Albumin is the most abundant serum protein and plays different roles, such as in the maintenance of colloid osmotic pressure, binding and transport of solutes and free radical scavenging (29). Serum albumin serves as a nutritional marker because hepatic synthesis of albumin is primarily affected by colloid osmotic pressure, inflammation and nutritional status (19, 29). 
A

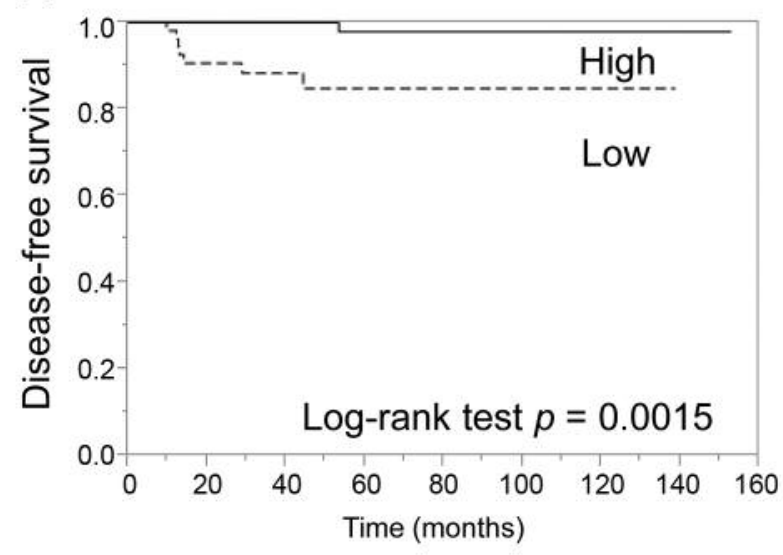

B

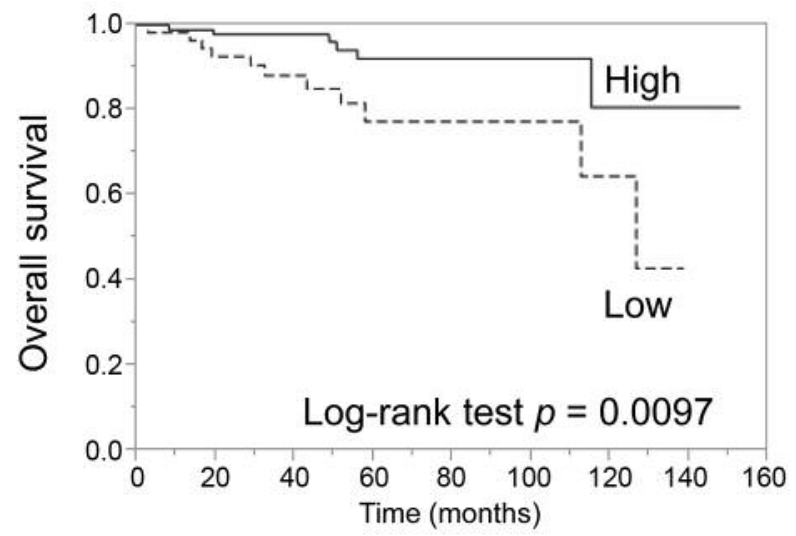

Figure 2. Association of the albumin to globulin ratio (AGR) with survival of patients with colon cancer without lymph node metastasis. KaplanMeier analysis of disease-free $(A)$ and overall $(B)$ survival in patients with colon cancer according to the preoperative AGR. Patients were divided into groups with high or low AGR according to whether their AGR was 1.32 or higher, or lower than 1.32, respectively.

A

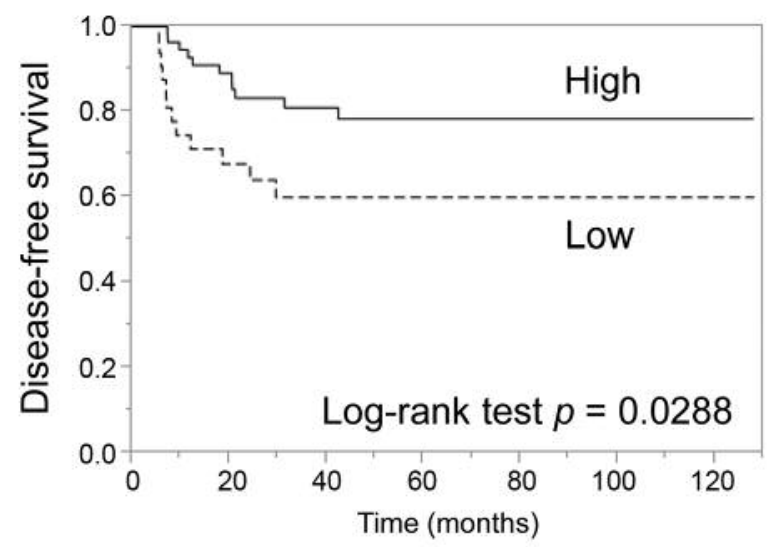

B

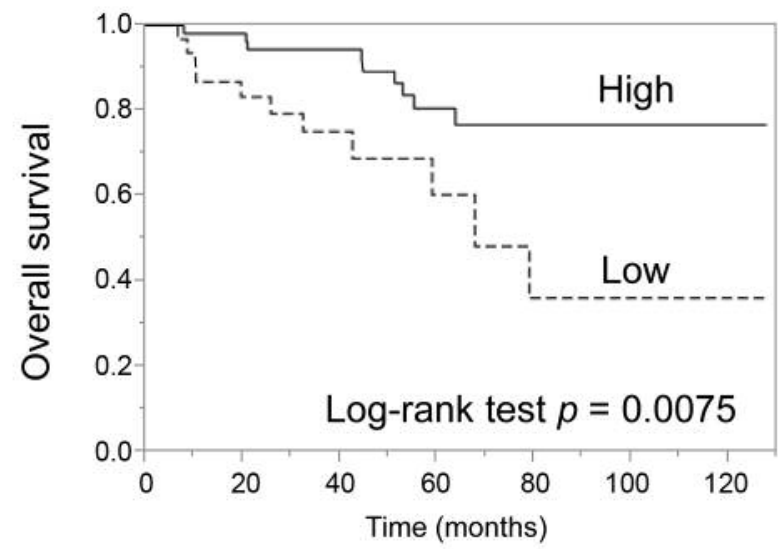

Figure 3. Association of the albumin to globulin ratio (AGR) with the survival of patients with lymph node metastasis of colon cancer. KaplanMeier analysis of disease-free $(A)$ and overall $(B)$ survival according to preoperative AGR. Patients were divided into groups with high or low AGR according to whether their AGR was 1.32 or higher, or lower than 1.32, respectively.

Furthermore, albumin preferentially accumulates in tumour tissues, and its degradation products serve as nutritional sources for tumour development (30).

In contrast, serum globulins comprise carrier proteins, immunoglobulins, complement factors and enzymes, which are mainly synthesized in liver (19). Globulins include acutephase proteins such as C-reactive protein, serum amyloid A, $\alpha$-1-acid glycoprotein and $\alpha$-1-antichymotrypsin (31). Approximately $25 \%$ of cancers are initiated or promoted by chronic inflammation associated with infection or inflammatory conditions of diverse origins (32). The release of pro-inflammatory cytokines stimulated by cancer-related inflammation increases the synthesis of these acute-phase proteins and decreases the synthesis of albumin (33). Hypoalbuminemia and hyperglobulinemia should, therefore, be significantly associated with cancer development and progression. Furthermore, the AGR is a combination of these two predictors of adverse outcome and is less affected by alterations in blood constituents, such as dehydration and fluid retention, which may further enhance its predictive value.

Low AGR is associated with poor oncological outcomes of patients with CRC with metastatic disease at all stages (20), as well as those with unresectable metastatic disease (22), and patients with rectal cancer who undergo 
Table IV. Cox proportional hazards model analysis of predictors of disease-free survival of patients with stage I-II colon cancer without lymph node metastasis.

\begin{tabular}{|c|c|c|c|c|}
\hline Factor & Univariate $\mathrm{HR}(95 \% \mathrm{CI})$ & $p$-Value & Multivariate HR $(95 \% \mathrm{CI})$ & $p$-Value \\
\hline Gender: $\mathrm{M} v s . \mathrm{F}$ & $0.86(0.2-3.65)$ & 0.83 & & \\
\hline Age: $\geq 70 v s .<70$ Years & $0.15(0.008-0.82)$ & 0.026 & $0.14(0.01-0.82)$ & 0.027 \\
\hline Location: Right $v s$. left & $1.59(0.39-7.73)$ & 0.52 & & \\
\hline Tumor size: $\geq 40 \mathrm{vs} .<40 \mathrm{~mm}$ & $2.0(0.44-10.2)$ & 0.36 & & \\
\hline Histology: Well/mod diff $v s$. poorly diff, muc & $9.38(1.92-38.4)$ & 0.0087 & $3.33(0.65-14.8)$ & 0.14 \\
\hline Tumor invasion: T4 vs. non-T4 & $4.77(0.98-19.5)$ & 0.053 & & \\
\hline Vascular invasion: Yes vs. no & $2.75(0.67-13.4)$ & 0.15 & & \\
\hline Lymphatic invasion: Yes $v s$. no & n.a. & n.a & & \\
\hline CEA: $\geq 5$ vs. $<5 \mathrm{ng} / \mathrm{ml}:$ Yes $v s$. no & $0.74(0.11-3.47)$ & 0.72 & & \\
\hline AGR: Low $(<1.32) v s$. high $(\geq 1.32)$ & $13.4(2.39-251.4)$ & 0.0018 & $12.4(1.97-239.1)$ & 0.0054 \\
\hline
\end{tabular}

M: Male; F: female; mod: moderately; diff: differentiated; muc: mucinous; CEA: carcinoembryonic antigen; AGR: albumin-to-globulin ratio; HR: hazard ratio; CI: confidence interval.

Table V. Cox proportional hazards model analysis of the predictors of overall survival of patients with stage I-II colon cancer without lymph node metastasis.

\begin{tabular}{|c|c|c|c|c|}
\hline Factor & Univariate HR (95\% CI) & $p$-Value & Multivariate HR (95\% CI) & $p$-Value \\
\hline Gender: $\mathrm{M} v s . \mathrm{F}$ & $2.42(0.89-7.66)$ & 0.083 & & \\
\hline Age: $\geq 70 v s .<70$ Years & $1.26(0.48-3.37)$ & 0.63 & & \\
\hline Location: Right $v s$. left & $0.62(0.23-1.62)$ & 0.33 & & \\
\hline Tumor size: $\geq 40 v s .<40 \mathrm{~mm}$ & $0.73(0.24-2.0)$ & 0.54 & & \\
\hline Histology: Well/mod diff $v s$. poorly/diff, muc & $4.49(1.0-14.9)$ & 0.05 & $2.76(0.6-9.47)$ & 0.17 \\
\hline Tumor invasion: T4 vs. non-T4 & $2.39(0.67-6.76)$ & 0.16 & & \\
\hline Vascular invasion: Yes vs. no & $4.49(1.55-16.2)$ & 0.0049 & $3.45(1.17-12.6)$ & 0.025 \\
\hline Lymphatic invasion: Yes vs. no & $2.12(0.68-9.3)$ & 0.21 & & \\
\hline CEA: $\geq 5 v s .<5 \mathrm{ng} / \mathrm{ml}$ & $0.75(0.21-2.19)$ & 0.62 & & \\
\hline AGR: Low $(<1.32) v s$. high $(\geq 1.32)$ & $2.83(1.08-7.81)$ & 0.034 & $3.17(1.11-10.3)$ & 0.031 \\
\hline
\end{tabular}

M: Male; F: female; mod: moderately; diff: differentiated; muc: mucinous; CEA: carcinoembryonic antigen; AGR: albumin-to-globulin ratio; HR: hazard ratio; $\mathrm{CI}$ : confidence interval.

preoperative chemoradiotherapy (21). In contrast, for the first time to our knowledge, we demonstrate here that the preoperative serum AGR is significantly associated with the prognostic outcomes of patients with $\mathrm{CC}$ who underwent surgery with curative intent. Thus, the AGR was an independent predictive factor of poor OS and DFS of patients with stage I-III disease and patients with stage I-II disease, respectively.

These results are provocative because evaluation of the preoperative AGR may influence the choice of therapy. The ESMO and NCCN guidelines recommend administering adjuvant chemotherapy to patients with stage II CC who undergo surgery with curative intent with risk factors such as stage T4; poorly differentiated histology, including signet ring and mucinous tumour; lymphovascular invasion; perineural invasion; obstruction; perforation and $<13$ lymph nodes in the surgical specimen $(4,6)$. Although we selected several pathological risk factors of recurrence of stage I-II $\mathrm{CC}$, such as stage T4, poorly differentiated histology and vascular invasion that were identified using univariate analysis, multivariate analysis revealed that a low preoperative AGR was a more accurate indicator of recurrence. Thus, the preoperative AGR may represent a novel, promising and convenient biomarker that will facilitate the decision to administer adjuvant therapy to patients with CC without lymph node metastasis (stage I-II).

In contrast, ESMO and NCCN guidelines recommend adjuvant chemotherapy for all eligible patients with lymph node metastasis $(4,6)$, and an oxaliplatin-based regimen is standard adjuvant treatment (34). However, not all patients benefit from adjuvant chemotherapy because they experience severe adverse effects, such as neurotoxicity. Thus, patients have either a good prognosis or tumours that do not respond to certain chemotherapy regimens (35). Further research is, 
therefore, required to investigate the indicators of early recurrence, and of poor prognosis in patients with lymph node metastasis (stage III).

Survival analysis revealed that patients with stage III CC with low AGR had shorter DFS and OS compared with those with high AGR. Furthermore, multivariate analysis revealed that low AGR was an independent indicator of shorter OS and DFS of these patients. Thus, the AGR may facilitate the choice of the most feasible adjuvant chemotherapy for patients with lymph node metastasis.

Another change of therapeutic strategy may involve preoperative intervention according to the AGR, which is a marker for nutritional status, inflammation and poor outcome. Therefore, nutritional support and anti-inflammatory therapy may contribute to improved outcomes for patients with low AGR. For example, improved preoperative nutritional status reduces the length of hospitalization (36-38) and postoperative complications (38-40) of patients with certain cancer types, including CRC. Studies investigating the ability of anti-inflammatory therapy to prevent or treat CRC have been reported (41). Our present findings indicate that survival may be extended by improving nutrition and mitigating inflammation, and if these findings are validated by clinical trials, the time of surgery can be optimized to when these interventions achieve the optimal AGR.

Our study is limited because of its retrospective design and small sample size. Moreover, the data were acquired from a single centre and we were unable to determine if patients were administered different adjuvant chemotherapy regimens. Finally, the minimum 3-year follow-up may have been insufficient for comprehensive evaluations of oncological outcomes.

In conclusion, this study is the first, to our knowledge, to report that the AGR was an independent predictive marker of OS and DFS of patients with stage I-III and stage I-II CC. The AGR is an index that is easy to determine, and our findings promise to assist clinicians in identifying patients at high risk of recurrence before they undergo surgery and may improve outcomes when used as a marker to optimize the administration of adjuvant chemotherapy independently of TNM stage.

\section{References}

1 Torre LA, Bray F, Siegel RL, Ferlay J, Lortet-Tieulent J and Jemal A: Global cancer statistics, 2012. CA Cancer J Clin 65: 87-108, 2015.

2 Fahy BN: Follow-up after curative resection of colorectal cancer. Ann Surg Oncol 21: 738-746, 2014.

3 Kobayashi H, Mochizuki H, Sugihara K, Morita T, Kotake K, Teramoto T, Kameoka S, Saito Y, Takahashi K, Hase K, Oya M, Maeda K, Hirai T, Kameyama M, Shirouzu K and Muto T: Characteristics of recurrence and surveillance tools after curative resection for colorectal cancer: a multicenter study. Surgery 141 : $67-75,2007$
4 Benson AB, 3rd, Venook AP, Bekaii-Saab T, Chan E, Chen YJ, Cooper HS, Engstrom PF, Enzinger PC, Fenton MJ, Fuchs CS, Grem JL, Hunt S, Kamel A, Leong LA, Lin E, Messersmith W, Mulcahy MF, Murphy JD, Nurkin S, Rohren E, Ryan DP, Saltz L, Sharma S, Shibata D, Skibber JM, Sofocleous CT, Stoffel EM, Stotsky-Himelfarb E, Willett CG, Gregory KM, Freedman-Cass DA and National Comprehensive Cancer N: Colon cancer, version 3.2014. J Natl Compr Canc Netw 12: 1028-1059, 2014.

5 Benson AB, 3rd, Bekaii-Saab T, Chan E, Chen YJ, Choti MA, Cooper HS, Engstrom PF, Enzinger PC, Fakih MG, Fuchs CS, Grem JL, Hunt S, Leong LA, Lin E, Martin MG, May KS, Mulcahy MF, Murphy K, Rohren E, Ryan DP, Saltz L, Sharma S, Shibata D, Skibber JM, Small W Jr., Sofocleous CT, Venook AP, Willett CG, Freedman-Cass DA and Gregory KM: Rectal cancer. J Natl Compr Canc Netw 10: 1528-1564, 2012.

6 Labianca R, Nordlinger B, Beretta GD, Brouquet A, Cervantes A and Group EGW: Primary colon cancer: ESMO Clinical Practice Guidelines for diagnosis, adjuvant treatment and followup. Ann Oncol 21(Suppl 5): v70-77, 2010.

7 Bockelman C, Engelmann BE, Kaprio T, Hansen TF and Glimelius B: Risk of recurrence in patients with colon cancer stage II and III: a systematic review and meta-analysis of recent literature. Acta Oncol 54: 5-16, 2015.

8 Galizia G, Lieto E, Zamboli A, De Vita F, Castellano P, Romano C, Auricchio A, Cardella F, De Stefano L and Orditura M: Neutrophil to lymphocyte ratio is a strong predictor of tumor recurrence in early colon cancers: A propensity score-matched analysis. Surgery 158: 112-120, 2015.

9 Maeda K, Shibutani M, Otani H, Nagahara H, Ikeya T, Iseki Y, Tanaka H, Muguruma K and Hirakawa K: Inflammation-based factors and prognosis in patients with colorectal cancer. World J Gastrointest Oncol 7: 111-117, 2015.

$10 \mathrm{Lu} \mathrm{H}$, Ouyang W and Huang C: Inflammation, a key event in cancer development. Mol Cancer Res 4: 221-233, 2006.

11 Roxburgh CS and McMillan DC: Cancer and systemic inflammation: treat the tumour and treat the host. Br J Cancer 110: 1409-1412, 2014.

12 Coussens LM and Werb Z: Inflammation and cancer. Nature 420: 860-867, 2002.

13 Miki C, Konishi N, Ojima E, Hatada T, Inoue Y and Kusunoki M: C-reactive protein as a prognostic variable that reflects uncontrolled up-regulation of the IL-1-IL-6 network system in colorectal carcinoma. Dig Dis Sci 49: 970-976, 2004.

14 Gabay C and Kushner I: Acute-phase proteins and other systemic responses to inflammation. N Engl J Med 340: 448-454, 1999.

15 Laird BJ, Kaasa S, McMillan DC, Fallon MT, Hjermstad MJ, Fayers P and Klepstad P: Prognostic factors in patients with advanced cancer: a comparison of clinicopathological factors and the development of an inflammation-based prognostic system. Clin Cancer Res 19: 5456-5464, 2013.

16 Li MX, Liu XM, Zhang XF, Zhang JF, Wang WL, Zhu Y, Dong J, Cheng JW, Liu ZW, Ma L and Lv Y: Prognostic role of neutrophil-to-lymphocyte ratio in colorectal cancer: a systematic review and meta-analysis. Int J Cancer 134: 2403-2413, 2014.

17 Kwon HC, Kim SH, Oh SY, Lee S, Lee JH, Choi HJ, Park KJ, Roh MS, Kim SG, Kim HJ and Lee JH: Clinical significance of preoperative neutrophil-lymphocyte versus platelet-lymphocyte ratio in patients with operable colorectal cancer. Biomarkers 17: 216-222, 2012 
18 Suh B, Park S, Shin DW, Yun JM, Keam B, Yang HK, Ahn E, Lee $\mathrm{H}$, Park JH and Cho B: Low albumin-to-globulin ratio associated with cancer incidence and mortality in generally healthy adults. Ann Oncol 25: 2260-2266, 2014.

19 Nazha B, Moussaly E, Zaarour M, Weerasinghe C and Azab B: Hypoalbuminemia in colorectal cancer prognosis: Nutritional marker or inflammatory surrogate? World J Gastrointest Surg 7: 370-377, 2015.

20 Azab B, Kedia S, Shah N, Vonfrolio S, Lu W, Naboush A, Mohammed F and Bloom SW: The value of the pretreatment albumin/globulin ratio in predicting the long-term survival in colorectal cancer. Int J Colorectal Dis 28: 1629-1636, 2013.

21 Li Q, Meng X, Liang L, Xu Y, Cai G and Cai S: High preoperative serum globulin in rectal cancer treated with neoadjunctive chemoradiation therapy is a risk factor for poor outcome. Am J Cancer Res 5: 2856-2864, 2015.

22 Shibutani M, Maeda K, Nagahara H, Ohtani H, Iseki Y, Ikeya T, Sugano $\mathrm{K}$ and Hirakawa $\mathrm{K}$ : The pretreatment albumin to globulin ratio predicts chemotherapeutic outcomes in patients with unresectable metastatic colorectal cancer. BMC Cancer 15: $347,2015$.

23 Azab BN, Bhatt VR, Vonfrolio S, Bachir R, Rubinshteyn V, Alkaied H, Habeshy A, Patel J, Picon AI and Bloom SW: Value of the pretreatment albumin to globulin ratio in predicting longterm mortality in breast cancer patients. Am J Surg 206: 764770, 2013.

24 Yao Y, Zhao M, Yuan D, Gu X, Liu H and Song Y: Elevated pretreatment serum globulin albumin ratio predicts poor prognosis for advanced non-small cell lung cancer patients. J Thorac Dis 6: 1261-1270, 2014.

25 Zhang B, Yu W, Zhou LQ, He ZS, Shen C, He Q, Li J, Liu LB, Wang C, Chen XY, Fan Y, Hu S, Zhang L, Han WK and Jin J: Prognostic significance of preoperative albumin-globulin ratio in patients with upper tract urothelial carcinoma. PLoS One 10: e0144961, 2015.

26 Sobin LH, Gospodarowicz MK and Wittekind C: TNM Classification of Malignant Tumours (7th edn).Wiley-Blackwell: Chichester, 2009.

27 Schmoll HJ, Van Cutsem E, Stein A, Valentini V, Glimelius B, Haustermans K, Nordlinger B, van de Velde CJ, Balmana J, Regula J, Nagtegaal ID, Beets-Tan RG, Arnold D, Ciardiello F, Hoff P, Kerr D, Kohne CH, Labianca R, Price T, Scheithauer W, Sobrero A, Tabernero J, Aderka D, Barroso S, Bodoky G, Douillard JY, El Ghazaly H, Gallardo J, Garin A, Glynne-Jones R, Jordan K, Meshcheryakov A, Papamichail D, Pfeiffer P, Souglakos I, Turhal S and Cervantes A: ESMO Consensus Guidelines for management of patients with colon and rectal cancer. a personalized approach to clinical decision making. Ann Oncol 23: 2479-2516, 2012.

28 Quasar Collaborative G, Gray R, Barnwell J, McConkey C, Hills RK, Williams NS and Kerr DJ: Adjuvant chemotherapy versus observation in patients with colorectal cancer: a randomised study. Lancet 370: 2020-2029, 2007.

29 Truong A, Hanna MH, Moghadamyeghaneh Z and Stamos MJ: Implications of preoperative hypoalbuminemia in colorectal surgery. World J Gastrointest Surg 8: 353-362, 2016.
30 Stehle G, Sinn H, Wunder A, Schrenk HH, Stewart JC, Hartung G, Maier-Borst W and Heene DL: Plasma protein (albumin) catabolism by the tumor itself--implications for tumor metabolism and the genesis of cachexia. Crit Rev Oncol Hematol 26: 77-100, 1997.

31 Peracaula R, Sarrats A and Rudd PM: Liver proteins as sensor of human malignancies and inflammation. Proteomics Clin Appl 4: 426-431, 2010.

32 Balkwill FR and Mantovani A: Cancer-related inflammation: common themes and therapeutic opportunities. Semin Cancer Biol 22: 33-40, 2012.

33 Tisdale MJ: Cancer cachexia. Langenbecks Arch Surg 389: 299305, 2004.

34 Labianca R, Nordlinger B, Beretta GD, Mosconi S, Mandala M, Cervantes A, Arnold D and Group EGW: Early colon cancer: ESMO Clinical Practice Guidelines for diagnosis, treatment and follow-up. Ann Oncol 24: vi64-72, 2013.

35 Pahlman LA, Hohenberger WM, Matzel K, Sugihara K, Quirke $\mathrm{P}$ and Glimelius B: Should the benefit of adjuvant chemotherapy in colon cancer be re-evaluated? J Clin Oncol 34: 1297-1299, 2016.

36 Liu MY, Tang HC, Hu SH, Yang HL and Chang SJ: Influence of preoperative peripheral parenteral nutrition with micronutrients after colorectal cancer patients. Biomed Res Int 2015: 535431, 2015.

37 Noblett SE, Watson DS, Huong H, Davison B, Hainsworth PJ and Horgan AF: Pre-operative oral carbohydrate loading in colorectal surgery: a randomized controlled trial. Colorectal Dis 8: 563-569, 2006.

$38 \mathrm{Xu} \mathrm{J}$, Zhong $\mathrm{Y}$, Jing $\mathrm{D}$ and $\mathrm{Wu} \mathrm{Z}$ : Preoperative enteral immunonutrition improves postoperative outcome in patients with gastrointestinal cancer. World J Surg 30: 1284-1289, 2006.

39 Horie H, Okada M, Kojima M and Nagai H: Favorable effects of preoperative enteral immunonutrition on a surgical site infection in patients with colorectal cancer without malnutrition. Surg Today 36: 1063-1068, 2006.

40 Bozzetti F, Gavazzi C, Miceli R, Rossi N, Mariani L, Cozzaglio L, Bonfanti G and Piacenza S: Perioperative total parenteral nutrition in malnourished, gastrointestinal cancer patients: a randomized, clinical trial. J Parenter Enteral Nutr 24: 7-14, 2000.

41 Park JH, McMillan DC, Horgan PG and Roxburgh CS: The impact of anti-inflammatory agents on the outcome of patients with colorectal cancer. Cancer Treat Rev 40: 68-77, 2014. 